\title{
O reencantamento da escola: um paradigma ético-éstético na educação
}

The re-enchantment of school: an ethico-aesthetic paradigm in education

\section{Resumo}

O presente artigo aborda a instituição Escola a partir de um paradigma ético-estético via seus processos de criação. Busca-se problematizar como tal paradigma pode alterar os contornos institucionais e os seus modos de subjetivação. Considera-se que a Escola é composta, simultaneamente, por um plano de organização que mantém as formas e os estriamentos, e, por um plano de consistência que compõe os espaços lisos mutantes. 0 foco deste artigo dar-se-á sobre o plano de consistência, uma vez que este abriga os processos de criação e as possibilidades de devir. Conceber uma educação voltada para os devires é um posicionamento político - uma política dos devires - baseado em uma ética que só pode ser concebida, juntamente, com a estética, uma vez que entende-se que a construção ética forma-se pelas atitudes estéticas que cada experiência educacional exige. Enfim, pretende-se transgredir clichês de representação sobre a própria Escola como um lugar instituído, ausente de transformação. Busca-se extrair, desta rocha-escola calcificada pelos estriamentos, os seus fluxos, devires e multiplicidades.

Palavras-chave: escola, paradigma ético-estético, criação e devires.

\begin{abstract}
The present article analyzes the School institution through an ethico-aesthetic paradigm via its creative processes. It aims at problematizing how this paradigm can change the School institutional limits and its means of subjectivation. We consider that the School is built, simultaneously, by an organization plane which maintains forms and striations, as well as a consistency plane which composes the smooth mutable spaces. The focus of this article will be on the consistency plane, since it hosts the creative processes and the changing possibilities. To conceive an education that is concerned with changes is a political statement - a policy of change - based on a type of ethics which can only be conceived along with aesthetics once we consider that ethical construction is formed by the aesthetic attitudes that each educational experience requires. In short, we intend to transgress clichés of representation about the School as an instituted place lacking transformation. We crave to extract from this hardened-School calcified by striations, its flows, transformations and multiplicities.
\end{abstract}

Keywords: school, ethico-aesthetic paradigm, creation, transformations.

O presente artigo visa pensar de que modo uma abordagem realizada a partir de um paradigma ético-estético pode alterar os contornos institucionais, as práticas cotidianas e os modos de subjetivação da Escola na atualidade. Coloca-se, aqui, o intento de que a Escola seja um lugar de descobertas; politicamente, calcada em uma educação que faça amizade com o caos a fim de ultrapassar o senso comum, os clichês que calam problematizações e transpor a permanência no plano da forma dada que exclui os devires. Este artigo propõe justamente considerar que a Escola é formada não apenas 
por um plano de organização e desenvolvimento que visa à concretização e conservação da forma, sobretudo, também, por um plano de consistência que desencadeia devires ao escrever, pintar, compor, ler, falar e brincar. Devir como meio de estar, continuamente, tornando-se, constituindo-se em um processo ético-estético.

Fazer amizade com o caos não implica em uma Escola caótica com regras aleatórias que despotencializariam a construção do saber, um local onde tudo pode. Enfrentar o caos, ao contrário, é ter a chance de mudar quando já não se pode mais continuar do mesmo modo, como Deleuze coloca: "Toda una vida no orgánica, porque el organismo no es la vida, la aprisiona" (2002, p. 52). Considerando a Escola como um organismo institucional, caso o organismo não esteja constantemente se desorganizando e recompondo, ele aprisiona a vida. Questiona-se porque não incluir os desvios, os não saberes, o inusitado, o imprevisível na desconstrução do organismo Escola? Não será esta sua potência de vida, no lugar de somente se ficar pensando sobre novas maneiras de organizá-la, de estriá-la cada vez mais? Buscar a vida em sua intensidade estética de criação não será o fim ético maior?

Afirma-se, aqui, a inseparabilidade das dimensões ética e estética na Escola via seus processos de criação, ou melhor, na vida, uma vez que se entende que a construção ética forma-se pelas atitudes estéticas que cada experiência educacional cotidiana exige. De acordo com Bakthin (BAKTHIN apud EMERSON, 2003, p. 263),

Embora constituam esferas distintas, o ético e o estético são indispensáveis um ao outro, e sua interação pode ajudar-nos a resolver alguns dos problemas mais insuportáveis da vida. Como faço para ficar do lado de fora de minha vida - com sua dor, sua indignidade, suas oportunidade perdidas e seus obstáculos futuros - de modo a moldá-la como algo com que eu possa viver, isto é, moldá-la como moldaria uma criação artística?

O paradigma ético-estético encontra-se nos processos de criação presentes na Escola, não somente na sala de aula, mas em suas composições espaciais, subjetivas, perceptivas e, mesmo, institucionais.

\section{Multiplicidades da percepção}

Talvez, primeiramente, deve-se considerar que o que chamamos de Escola constitui-se de acordo com a percepção que se tenha dela, não sendo um bloco homogêneo e universal. Há uma diversidade de percepções, sendo que aponta-se aqui duas dimensões distintas: uma dimensão perceptível da forma e outra imperceptível das forças (que nos 
escapa constantemente), isto é, que há dois níveis na Escola, sendo cada um regido por leis próprias. Deleuze e Guattari (1997b) apontam a possibilidade de se movimentar pelo território através de suas distintas dimensões. Pelas dimensões pode-se transitar em um nível macro, perceptível e em um outro micro, muitas vezes, imperceptível.

No macro, a Escola apresenta-se institucionalizada, uma vez que já tem uma língua própria, uma linguagem instituída, um plano de organização e desenvolvimento regido por um aparelho disciplinar e de controle, dentre outros. No micro, age um contradiscurso que visa experimentar um espaço pedagógico onde desterritorializam-se os modos de subjetivação em jogo. "Tais dimensões, macro e micro, produzem uma tensão na Escola por onde pulsa a vida. Uma vontade de eternidade, de conservação do status quo; e outra, de destruição do presente que afirma o mesmo, de busca de novos trajetos" (OLIVEIRA, 2006b, p.142). Como Nietzsche (2001) coloca, uma tensão de vida entre a vontade de verdade que nos forma e a vontade de poder que nos liberta ao nos lançar no caos.

Visualmente, é como se a mesma Escola fosse constituída por dois espaços diferenciados, no entanto, simultâneos. Um espaço estruturado, já marcado, estriado; e outro liso, cheio de potencialidades a serem atualizadas. Tal visualização de espaço estriado e liso é aludida por Deleuze e Guattari (1997b, p. 180; 185), quando apontam a distinção entre estes espaços, bem como sua interdependência:

[...] devemos lembrar que os dois espaços só existem de fato graças às misturas entre si: o espaço liso não pára de ser traduzido, transvertido num espaço estriado; o espaço estriado é constantemente revertido, devolvido a um espaço liso. [...] Enquanto no espaço estriado as formas organizam uma matéria, no liso materiais assinalam forças ou lhes servem de sintomas.

São dois planos sobre o mesmo território, sendo que em cada espaço está implícito o outro: não se pode estriar se em algum momento não existiu um espaço liso; assim como o espaço liso não é imaculado e não se conserva in aeternum sem estriamentos. Pode-se dizer que o espaço liso é a potência de desterritorialização da Escola, a capacidade de perder-se, de se misturar para se achar novamente em outro estriamento não experimentado; é a capacidade de criação estética.

A Escola estriada exige a avaliação por notas, a recognição, as normas estabelecidas para serem cumpridas, o currículo, os papéis definidos (funcionários, professores, alunos e pais); necessidades para se conservar a instituição como tal. Entretanto o estriamento 
não se dá apenas na cobrança do cumprimento das regras de maneira fixa, mas também na expectativa de que elas vão ser cobradas: os alunos realizam algo esperando a avaliação quantitativa, os pais aguardam certas atitudes a serem cumpridas pelos professores e funcionários, os professores já estipulam previamente formas de aprendizado. Há uma tradição naturalizada dos modos de fazer, um caminho já trilhado por onde seguir, um certo "não saber fazer de outra maneira". Assim, mesmo em um espaço ainda não assinalado já existem marcas invisíveis que conduzem suas direções. A Escola não é um espaço liso imparcial, uma vez que nos encontramos sempre sobre um espaço estriado que nos protege do caos, da desagregação que é imanente ao plano micropolítico da própria Escola.

O plano liso não vai se dar sobre o nada, sobre a ausência de um estriamento, mas sobre o próprio estriamento. O liso não é o limpo, mas um afrontamento com o caos, uma perda, momentânea, do contorno do estriamento. Deparar-se com o liso é tentar ultrapassar as marcas prontas, criar outros trajetos, deixar-se capturar pela proximidade do momento, ficando sem foco a forma-escola. Como Deleuze e Guattari falam ao remeter Cézanne (1997b, p. 204):

Cézanne falava da necessidade de já não ver o campo de trigo, de ficar próximo demais dele, perder-se sem referência, em espaço liso. A partir desse momento pode nascer a estriagem: o desenho, os estratos, a terra, a "cabeçuda geometria", a "medida do mundo", as "camadas geológicas", tudo cai a prumo... Sob pena de que o estriado, por sua vez, desapareça numa "catástrofe", em favor de um novo espaço liso, e de um outro espaço estriado.

O liso contém a Escola como obra de arte. Não se pode ter uma Escola em constante afronto com o caos, entretanto também não se pode estar sempre pelo estriado, uma vez que o caos não pára de afrontar. A presença do liso como potência de diferir, de criar, de contágio do caos, de não reprimir as forças da vida.

Faz-se necessário uma experiência estética para se mover pelo espaço liso. Demarca-se o território justamente no devir-expressivo, na emergência das qualidades próprias como cores, odores, sons, luzes, expressões e outras. De acordo com Deleuze e Guattari (1997a, p. 123):

O território seria o efeito da arte.[...] Não no sentido em que essas qualidades pertenceriam a um sujeito, mas no sentido em que elas desenham um território que pertencerá ao sujeito que as traz consigo ou que as produz. [...] as marcas territoriais são ready-made. De qualquer coisa, fazer uma matéria de expressão. 
A experiência estética atribui expressividade às qualidades da matéria. Não é impor uma forma à matéria, mas tornar expressiva a própria matéria, ou seja, não é taxar uma identidade à matéria, mas atualizá-la em sua contingência. Isto é, conferir um caráter mutante às marcas da Escola, às práticas pedagógicas a partir de suas qualidades. Entretanto deve-se observar que assim como há necessidade de expressão, de sentido, em contraponto, há imposições do senso comum e dos esteriótipos.

No espaço liso, compomos Escolas invisíveis. Fazendo alusão à As Cidades Invisíveis de Ítalo Calvino (1990), há inúmeras escolas dentro da mesma. Torna-se impossível uma identidade única, uma vez que ao se mover pelas qualidades expressivas aparecem diversas identidades. Cada conjunto de qualidades configura uma escola. Como nas cidades que Marco Pólo cria (sem origens, mapas sem chegadas) cada uma tem um nome (todos femininos) com suas singularidades imperceptíveis a um viajante desatento. A cidade Olívia emerge de uma sensação no espaço liso e configura-se com suas particulares qualidades. Poder-se-ia, também, designar distintos nomes para as escolas que nos acometem no cotidiano. A escola torna-se plástica no espaço liso.

Em contraponto, o espaço estriado pode estar relacionado às normas escolares. De acordo com Cangüillem (1982), abordando o normal e o patológico, inexiste a ausência de normas. Neste sentido, não se pretende uma escola sem normas, que seria inviável. Contudo, sabemos que se ficamos sempre sobre os mesmos estriamentos, cumprindo as mesmas normas, estas nos tiram a potência e inibem a expansão da vida. A reprodução contínua sobre o estriado provoca uma paralisia diante dos obstáculos, uma incapacidade de opor-se ao poder, ficando aprisionado dentro de sistemas determinados. Perde-se a capacidade normativa ao apresentar deficiência de instituir normas diferentes sob novas condições; uma inépcia de renormatizar, de diferir, de mudar situações específicas que não funcionam mais. São carências da habilidade de conexão, de afetar e de ser afetado em um sistema restritivo. A criação de normas é da ordem da autonomia, ou seja, atitude de discutir normas vigentes e invenção de outras pertinentes às novas contingências com toda sua adversidade.

Neste sentido, se torna secundário um juízo de valores sobre as normas em si, no entanto, um questionamento de como se formam, de como se agenciam de maneiras diferenciadas. A Escola é formada por agenciamentos que reterritorializam, normatizam, estriam e estratificam, mas também que desterritorializam e provocam transgressões. Cabe-nos indagar como dá-se esta constituição do território, que tipo de movimento está 
presente entre os agenciamentos que territorializam e que desterritorializam, como dá-se a passagem entre os planos lisos e os estriados? Novamente, a abordagem deste artigo não se dá sobre as características, sujeitos, tipos de normas, mas sobre o modo como estes elementos compõem e constroem a Escola.

Percebe-se que propostas pedagógicas já trazem abertura, ou não, para o liso, para a autonomia. Há fazeres dentro da Escola que propiciam movimentos pelos planos e outros que condicionam a um determinado resultado. Fazeres que permitem contatos com o desconhecido, com o caos, com a desorganização como processo de construção do conhecimento. A Escola está sempre se formando a partir de seus fazeres que o restringem ou o expandem.

Tal tensão entre conservação e expansão constitui a Escola e a própria vida, uma vez que somente há vida se há tensão. Todavia, percebe-se que tal tensão não é isenta de intencionalidade. Há vontades que primam pela sobreposição, ou mesmo pela anulação, de um dos movimentos. Jogos de vontades que permitem, ou não, uma aproximação com o caos, com o desconhecido, com o plano estético de composição que foge de um controle previsível.

\section{Estratégias da vontade}

São vontades distintas que constroem realidades diferentes na Escola. Os elementos, as tensões, os movimentos estão presentes em todos os momentos, entretanto há inúmeras maneiras de arranjá-los. A realidade se apresenta como a contamos, escrevemos, imaginamos. Em Nietzsche (NIETZSCHE apud FOUCAULT, 1996) já se encontra que todo fazer humano é invenção de si e do mundo, uma vez que não existe uma realidade préexistente. Para ele, a criação faz parte da gênese da vida: o viver é ato de criação constante. Nada é natural: não é natural a natureza ser conhecida nem a relação entre o conhecimento e as coisas; é uma invenção humana conhecer a natureza.

Nietzsche opõe a invenção à origem ao buscar desnaturalizar a essência dos objetos, ao questionar as rememorações e linearidades. Mostra que não existe a coisa em si, mas invenções que são formas da poiesis humana. Delata o contra-senso da busca de um conhecimento absoluto que não se encontra nem no objeto nem no sujeito, uma vez que ambos pertencem ao mesmo processo de criação que está condicionado pelas estruturas atuantes que os compõe. 
Ao se pensar sobre os processos de criação, pressupõem-se os de cognição, pois estes se formam na tensão entre a busca constante de aparências e a conservação das mesmas. De acordo com Nietzsche (2001), tudo o que vive, vive na aparência, isto é, todas as ordenações inteligíveis que o ser constrói são aparências e não o real. O ser humano somente tem acesso às aparências, uma vez que o mundo, imerso no caos, the escapa em sua totalidade. Isto é, todo o vivido é aparência; todavia, há uma distinção fundamental entre o movimento de busca e de conservação das aparências. O de busca das aparências está ligado à vontade de poder como capacidade inventiva do ser; como movimento na direção de potência de vida e como busca de imagens que produzem o prazer. Como Deleuze nos diz sobre Nietzsche: "A vontade de poder, diz Nietzsche, não consiste em cobiçar nem sequer em tomar, mas em criar e dar. O Poder, como vontade de poder, não é o que a vontade quer, mas aquilo que quer na vontade (Dionísio em pessoa)" (1965, p. 22). Na vontade de poder, a vontade se apresenta embriagada pelos delírios oriundos do caos, por uma força que exige mover-se.

Vontade de poder, vontade que desacomoda e incomoda. Mesmo os mais cômodos em suas posições escolares, sentem, em um certo momento, que as situações podem ser diferenciadas, que há oportunidade de criação. Contrapondo-se à vontade de poder, Nietzsche (2001) aponta que a vontade de verdade visa a manutenção do estabelecido através da conservação das aparências. É um movimento que se fecha sobre si mesmo, fortalecendo o instituído e lutando pela sua permanência, bem como negando o caos com toda sua multiplicidade e mutabilidade. A vontade encerra-se em seu querer próprio diante da ameaça da mudança; almeja a fixação interna recusando as provocações do fora; e torna-se niilista ao bloquear a pulsão da potência de vida. A estes aspectos da vontade de verdade, Nietzsche identifica a ciência que também movimenta-se no sentido de inibir a capacidade inventiva quando almeja uma verdade fixa e absoluta. Assim, uma vez que a invenção não é permitida, a cognição restringe-se a reconhecer e afirmar o conhecido via a recognição. De acordo com Deleuze e Guattari: "[...] pensamento é criação, não vontade de verdade, como Nietzsche soube mostrar" (1992, p. 73). Podese, ainda, relacionar a vontade de verdade com o plano de estriamento da escola, e a vontade de poder com o plano liso de criação.

Do mesmo modo como a vontade de verdade se relaciona com a ciência pela sua força de fixação, adaptação e conservação, a vontade de poder se liga à arte pela sua capacidade criadora. Para Nietzsche (2001), a arte possibilita e estimula a vida, uma vez que tem como princípio a invenção: invenção de verdades, de mentiras, de mundos. 
Agustín Izquierdo (NIETZSCHE, 2001, p.15), no prólogo do livro Estética y teoria de las artes de Friedrich Nietzsche, escreve:

Frente a la opinión de que la vida es algo real, el ser o la verdad, Nietzsche sostiene que todo lo que vive, vive en la apariencia, en la ilusión, en la mentira, en el engaño, y es el arte el que produce estas apariencias, mentiras, ilusiones, que son la condición de la vida, su posibilidad.

A potência de vida está na multiplicidade, na alegria do diverso. Através da dimensão estética podemos ter acesso direto à criação como fundamento do viver, como o próprio Nietzsche (2001) coloca que na arte o homem imita a natureza, mas não as formas e sim a ação criadora mesma da natureza. Ou mencionando Bakthin, por Emerson (2003, p. 268):

Os humanos são criaturas que atribuem forma. É parte de nossa natureza ansiar por conclusão. Essa ânsia, segundo Bakhtin, é o instinto estético.[...] Como assinala Volkova: [...] Antes de reagir esteticamente, diz ela, o autor reage cognitiva, ética, psicológica, social e filosoficamente - e só então realiza a conclusão artística e estética do mundo. Este último movimento, embora condicionado por todos os outros, é o mais completo e puro.

O potencial de criação deve ser requerido na Escola. Mesmo, freqüentemente, na disciplina de Educação Artística se perde tal potencial; ficando sujeita a um "tarefismo" pelas propostas tecnicistas ou a um "espontaneismo" exagerado pelos trabalhos de livre expressão. A criação é experiência do pensamento que percorre todo fazer escolar. Há uma postura diferenciada, sobretudo política, ao se estimular e valorizar a criação no contexto escolar. Deve-se propiciar aos alunos capacidades inventivas, de não acomodação perante a vida, de invenção de mundos, como diz Nietzsche (2001). Em suma, na criação concebe-se uma visão estética do mundo a partir das experiências vividas.

\section{Devires da Escola}

Atrela-se, freqüentemente, a característica de conservação da escola ao seu papel institucional. A escola apresenta-se como uma das instituições base nas sociedades contemporâneas. Como instituição, cabe a ela instituir, conservar, durar. Mas o que se conserva e dura na instituição-escola? Faz-se necessário pensar a Escola como instituição social. Ela é um território construído e que constitui um plano social.

Ao se falar sobre instituição, inicialmente, pretende-se esclarecer sobre qual concepção se alude. As instituições são entendidas a partir de algumas referências de Deleuze, que as considera como elaborações feitas pelos sujeitos, como meios de satisfações artificiais 
para atender e transformar as tendências naturais. Como ele próprio nos diz (DELEUZE, 1997b, p. 135),

a instituição se apresenta sempre como um sistema organizado de meios [...] nos remetem a uma atividade social constitutiva de modelos, dos quais não somos conscientes, e que não se explica pela tendência ou pela utilidade, uma vez que esta última, como utilidade humana, pelo contrário, a supõe [...] a tendência é satisfeita por meios que não dependem dela.

Deleuze elucida que as tendências naturais não são iguais aos meios que a satisfazem, já que estes meios não são determinados por elas, mas por um arranjo social. Assim, considera-se primordial o reconhecimento da distinção entre instituição e tendência natural afim de que as instituições não sejam justificadas pelas tendências naturais que nos escapam em sua genealogia.

Ao encontro de Nietzsche, Deleuze aponta o natural como construção social. Os meios não podem ser naturalizados como tendências, como necessidades, uma vez que as tendências naturais se encontram atreladas exclusivamente às urgências do animal; as quais o ser humano não consegue apreender diretamente, já que é movido pelos meios sociais. Isto é, a tendência se satisfaz através dos meios, mas os meios - as instituições - não se explicam pela tendência em si, por exemplo: a necessidade de satisfação da tendência sexual não justifica os meios construídos artificialmente para satisfazê-la, como o casamento. As tendências nunca podem ser vistas de forma normatizada, pois caso isto ocorra ela já se tornou em instituição.

Deste modo, as instituições, como meio social de satisfação, devem ser questionadas, investigadas em seus motivos implícitos de existência e constituição. As instituições são sempre meios de satisfação fabricados socialmente e não advindos de necessidades naturais inatas no ser humano. Na instituição-escola inexiste um modo natural de aprendizagem, "se ensina assim, porque os alunos apreendem assim".

Outro aspecto, salientado por Deleuze e Guattari (1996), é a luta de forças que constituem as instituições. Elas são transversalizadas e atravessadas por forças de produção e reprodução, moleculares e molares. Nelas, travam-se lutas permanentes entre os processos instituídos, naturalizados, que buscam aprisionar o processo vital através de estratégias de normatização, de formas hegemônicas que almejam a conservação do poder e os processos instituintes, as forças de invenção de alteridade 
que afirmam as potências do viver. Movimentos de ruptura com uma produção de subjetividade assujeitada, submetida e de captura de produções de subjetividades livres.

Esta subversão entre o molar e o molecular está impressa em toda dobra-escola, e tanto um quanto o outro pode inibir e bloquear a potência do viver e o fluxo do desejo. Por isso, Deleuze e Guattari buscam compreender a binaridade molar e molecular, macropolítica e micropolítica para romper com a própria binaridade e explicitar o perigo existente em ambas. Admite-se esta binaridade a partir do pressuposto que o ser humano é um ser segmentário, sem unidade coerente. Segundo ambos autores (DELEUZE e GUATTARI, 1996, p. 90):

Toda sociedade, mas também todo indivíduo, são, pois, atravessados pelas duas segmentaridades ao mesmo tempo: uma molar e outra molecular. [...] se são inseparáveis, é porque coexistem, passam uma para a outra, segundo diferentes figuras como nos primitivos ou em nós - mas sempre uma pressupondo a outra. Em suma, tudo é político, mas toda política é ao mesmo tempo macropolítica e micropolítica.

Não se consegue fazer um recorte focando-se exclusivamente o macro ou o micro, o molar ou o molecular, pois ambos formam as tramas do tecido social e ambos são partícipes das relações de conservação ou não do poder. De acordo com Sílvio Gallo: "Se a educação maior é produzida na macropolítica, nos gabinetes, expressa nos documentos, a educação menor está no âmbito da micropolítica, na sala de aula, expressa nas ações cotidianas de cada um" (2003, p. 78). Em todo molar pulsa uma força molecular inaudível, bem como em todo molecular delineia-se uma estrutura molar. Como nos alertam Deleuze e Guattari (1996), há um perigo implícito em cada linha, em cada segmentaridade que é reconhecido não pela representação, mas pelos trajetos de suas misturas e distinções. Aponta-se uma Escola que sai dos seus trajetos marcados e percebe outros invisíveis, porém presentes.

\section{Agenciamentos do fazer}

Os múltiplos trajetos presentes não se fixam, contudo se constroem nos fazeres da Escola, em seus agenciamentos. Abordam-se, aqui, agenciamentos que não se resumem às relações entre sujeitos, ao humano; mas tudo o que acontece na Escola. Os sujeitos estão na Escola, assim como os sons, as imagens, os espaços, os tempos, os trajetos. 0 que se produz em um território não são sujeitos isolados, mas agenciamentos que extrapolam os sujeitos. Na Escola, quando as experiências cognitivas emergem como efeitos de agenciamentos, elas pertencem ao plano da vida indo além da escola. 
Deste modo, tal agenciamento é visto como coletivo, já que não é determinado pelas necessidades ou intenções particulares dos indivíduos. Na Escola, um trabalho provindo de um agenciamento coletivo se constitui como um efeito de contingências de um processo criativo e emerge como uma obra original e singular, já que é criada a partir dos jogos pertinentes aos agenciamentos entre os sujeitos e a própria obra, compostos por elementos singulares, em um recorte de espaço/tempo histórico. Assim, a criação não delimita-se apenas no objeto produzido, uma vez que a obra configura-se em todo plano de composição efetivado no agenciamento, ou seja, o agenciamento coletivo (espaço, tempo, obra, sujeitos, forças) é visto como causa/efeito por gerar-se no e pelo ato de criação. Segundo Deleuze: "Nós só podemos agenciar entre os agenciamentos" (DELEUZE e PARNET, 1998, p. 67).

Neste sentido, Deleuze, referindo-se aos enunciados, retira dos sujeitos a exclusiva função de produtores e remete aos agenciamentos, nos quais os sujeitos fazem ou não parte. Como ele próprio diz (DELEUZE e PARNET, 1998, p. 65):

\begin{abstract}
É sempre um agenciamento que produz os enunciados. Os enunciados não têm por causa um sujeito que agiria como sujeito da enunciação, tampouco não se referem a sujeitos como sujeitos de enunciado. O enunciado é o produto de um agenciamento, sempre coletivo, que põe em jogo, em nós e fora de nós, populações, multiplicidades, territórios, devires, afetos, acontecimentos.
\end{abstract}

Nesse processo, o sujeito não é a fonte da invenção, uma vez que a invenção é fruto do próprio produto (dos jogos pertinentes à obra) e das contingências do mundo. Ele participa da invenção ao ser inventado durante o processo. Invenção como um processo sem inventor, sem controle restritivo. Incide em um processo coletivo no qual o sujeito é apenas partícipe, protagonista coletivo e processual.

A idéia do agenciamento coletivo retira o foco sobre o sujeito criador e implementa sobre a criação. Os atores pedagógicos, quando imersos no processo de criação, são conduzidos pela experiência estética que indica trajetos imprevistos. Na criação, a ética da sala de aula é conduzida pela estética da experiência. Para Deleuze, a ética é ação e reflexão, é uma ética da matéria, uma vez que, há sempre a relação com o fora, com o coletivo, a coexistência do um e do múltiplo. Neste campo de agenciamentos em que são composições de materialidades a ética está inseparável da estética. 


\section{Pensamento, Arte e Escola}

A arte, com seus processos de criação, propõe novas experiências e outros modos de viver. Ela nos alforria do presente do qual se quer livrar, criando-se outros diferentes a partir de seu processo de autocriação. Pensar a Escola a partir de paradigmas éticoestéticos é pensá-la como obra de arte. A arte é uma experiência do pensamento e, neste sentido, uma prática ética, já que oferece ao ser humano o que é seu de direito, o próprio pensamento. Bem como uma construção estética do mundo ao fazer ver o que ainda não tem visibilidade e de atribuir sentido às novas composições inventadas. Através da arte se pode desacelerar o cotidiano produzindo outras dimensões do tempo e habitando o plano dos devires (OLIVEIRA, 2006a).

Desta forma, a arte se constitui como um pensamento profundo que potencializa a vida ao buscar a partir da estética uma realização ética ao superar a própria condição humana. As formas humanas se desgastam, precisando da criação para potencializar novas formas de viver.

Pensar uma educação voltada para os devires é um posicionamento político - uma política dos devires - baseado em uma ética que só pode ser concebida, juntamente, com a estética. Tal posicionamento consiste em recusar-se a sujeição do Mesmo e transitar pela criação que leva a compreensão a partir da experimentação. Na apresentação do livro, Escritos sobre Educação de Friedrich Nietzszche, Noélo Correia de Melo Sobrinho aponta que: "[...] esta nova educação pressupõe que a vida somente está justificada como fenômeno estético, como formação de si, como cultura, como uma empreitada de destruição/criação que indica novos modos de pensar inusitados até então" (NIETZSCHE, 2003, p. 37).

Em Deleuze e Guattari encontramos que "a arte não pensa menos que a filosofia, mas pensa por afectos e perceptos" (1992, p. 88). Um afecto, uma surpresa, uma abertura às descontinuidades e rachaduras. Uma experiência de aprendizagem de problematização e, concomitantemente, de invenção de mundo. Deleuze (1997) vê a arte como possibilidade de ir ao limite da linguagem onde se libertam os delírios, desvios e devaneios. Na linguagem que codifica, que impõem uma identidade, que nos torna sujeitos, mas que, também, permite o contato com a materialidade do concreto impregnada de virtualidades. 
A arte enfrenta o caos para, por um instante, chegar à sensação. A criança quer conhecer através da sensação. A experiência estética vem da medida em que eu me abro para aquilo que me olha. Os alunos escutam as músicas, olham as imagens, constroem composições, bem como as próprias imagens, sons, composições servem de espelhos por onde eles têm contato com suas virtualidades, com o que lhes estava intocado, embora presente. A arte é uma maneira de nos deixarmos presenciar. A imagem não é algo que eu vou conhecer, mas algo que vai fazer-me (des)conhecer, isto é, uma perturbação, uma impercepção da percepção, uma névoa virtual.

Pensar a escola como obra de arte consiste em deslocar, insistentemente, o próprio pensamento sobre a Educação. Busca-se investigar a partir do seu funcionamento, dos mecanismos implícitos em seu pensar, sentir e fazer. Para isso, procura-se desdobrar, distender ao máximo o evidenciável - a instituição escola -, chegando ao limite que possibilita a transgressão e o surgimento do inesperado e rompendo com a dialética da afirmação e negação. Conceitos tramados no e pelo fazer humano sobre um campo de composição que busca validar seus mais tênues elementos. Elementos estes que, muitas vezes, se fazem presentes por suas ausências, que se ordenam não devido às suas vontades próprias, mas pelos jogos que se estabelecem, pelas necessidades estéticas das composições nos processos de criação.

Uma Escola para a vida que abarca os desvios, as fragilidades e incertezas, as identidades mutáveis. Pensa-se uma Educação ligada à experiência, à vida, conforme Nietzsche (2003) nos mostra. Onde há uma ética da existência, coexiste uma estética da experiência implicada nas ações do cotidiano. Busca-se despertar experiências ainda não vividas, trajetos não percorridos, conversas não faladas, vontades não concretizadas. Conforme Nietzsche, citado por Rosa Maria Dias: "É preciso agir e viver para aprender e compreender - eis o preceito segundo o qual Nietzsche pretendia educar seus alunos" (1991, p. 27).

Liberar o tempo de seu compasso já marcado. Liberar a memória identitária para um inconsciente ontológico. Liberar o organismo-escola para organizações mutantes que tangenciam o caos. Uma educação como possibilidade de liberação, como o próprio Nietzsche (2003, p. 141) nos diz:

Teus verdadeiros educadores, aqueles que te formarão, te revelaram o que são verdadeiramente o sentido original e a substância fundamental da tua essência, algo que resiste absolutamente a qualquer educação e a qualquer formação, 
qualquer coisa em todo caso de difícil acesso, como um feixe compacto e rígido: teus educadores não podem ser outra coisa senão teus libertadores.

A Escola como potencial de liberdade: um desafio para a vida. Desafios que ficam abertos: pensar em que estamos nos tornando na escola? Quando um lugar (escola) se torna nosso? Quem é este que me olha de onde eu não estou? Nos olharmos de outro lugar: Escola como lugar de estranhamento. Enfim, transgredir os clichês de representação sobre a própria Escola como um lugar instituído, ausente de transformação. Mesmo que ela reduza o potencial da vida, há vida na escola, somente pelo fato de habitarmos nela durante um considerável tempo de nossas vidas. Cabe-nos extrair desta rocha-escola calcificada pelos estriamentos, os seus fluxos, seus devires e suas multiplicidades.

\section{Referências}

CANGUILLEM, G. O normal e o patológico. Rio de Janeiro: Forense, 1982.

CALVINO, Í. As cidades invisíveis. São Paulo: Cia das Letras, 1990.

DELEUZE, G. Nietzsche. Lisboa, Portugual: Edições 70, 1965.

G. Conversações 1972 - 1990. Rio de Janeiro: Editora 34, 1992.

G. Crítica e Clínica. São Paulo: Editora 34, 1997.

G. Francis Bacon: lógica de la sensación. Madrid: Arena Libros, 2002.

DELEUZE, G. Et GUATTARI, F. O que é filosofia? Rio de Janeiro: Editora 34, 1992.

G. Et GUATTARI, F. Mil platôs - capitalismo e esquizofrenia. Rio de Janeiro:

Ed.34, vol. 3, 1996.

G. Et GUATTARI, F. Mil platôs - capitalismo e esquizofrenia. São Paulo: Ed.34, vol. 4, 1997a.

G. Et GUATTARI, F. Mil platôs - capitalismo e esquizofrenia. São Paulo:

Ed.34, vol. 5, 1997b.

DELEUZE, G. Et PARNET, C. Diálogos. São Paulo: Editora Escuta, 1998.

DIAS, R. M. Nietzsche educador. São Paulo: Ed. Scipione, 1991.

EMERSON, C. Os cem primeiros anos de Mikhail Bakhtin. Rio de Janeiro: DIFEL, 2003.

FOUCAULT, M. A verdade e as formas jurídicas. Rio de Janeiro: Nau, 1996. 
GALLO, S. Deleuze e a Educação. Belo Horizonte: Autêntica, 2003.

OLIVEIRA, A. M. Um Olhar Sobre O Invisível: o duplo cognição e criação no territórioEscola. Dissertação Mestrado em Psicologia Social e Instituicional. Porto Alegre: PSICO UFRGS, 2006a.

OLIVEIRA, A. M., FONSECA, T. G. Os devires do território-escola: trajetos, agenciamentos e suas múltiplas paisagens. In: Educação e Realidade, vol. 31, jul/dez 2006b, p. 135-154.

NIETZSCHE, F. Estética y teoría de las artes. Madri: Editorial Tecnos, 2001. F. Escritos sobre educação. São Paulo: Ed. Loyola, 2003.

Andreia Machado Oliveira

Universidade Federal de Santa Maria

Tania Mara Galli Fonseca

Universidade Federal do Rio Grande do Sul

Recebido em:21/05/2013

Aprovado em: 15/10/2013 